\title{
Hybridization of Energy Storage Systems for Electric Transportation by Means of Bidirectional Power Electronic Converters
}

\author{
Ramy Georgious, Jorge García \\ Department of Electrical, Electronic, Computers and Systems Engineering, \\ University of Oviedo, Spain \\ E-mail: georgiousramy@uniovi.es
}

\begin{abstract}
This paper deals with the design of a Hybrid Energy Storage System (HESSs) for electric transportation such as Electric/Hybrid Vessel and Electric/Hybrid Train. The association of more than one Energy Storage Systems (ESSs) e.g., batteries which have different dynamics permit to take the advantages of the characteristics of both ESSs obtaining simultaneously a high energy density and high power density. This yields to a decrease in terms of the size of the main ESS and the total cost and an increase in terms of life span. The emulation of the batteries and with required control algorithm for the HESS are proposed. The design and the control of the HESSs is validated with the simulation in MATLAB/SIMULINK $®$ environment and also with the realtime emulation of batteries in a laboratory setup of a HESS. The real-time experimental results have been validated against PC simulations showing full consistency. The setup of the hardware of HESS can be used to test any technologies of batteries, being a low cost solution for testing and benchmarking.
\end{abstract}

Keywords-Energy Storage Systems, Hybrid Energy Storage Systems, Bidirectional Boost Converter, Electrical Transportation.

\section{INTRODUCTION}

The main purpose of Energy Storage Systems (ESSs) in applications such as electric transportation as well as microgrids or smart grids is to provide a temporary energy buffer between electrical power generators and loads or to provide a permanent energy to the loads in case of islanding mode [1]. These ESS, together with Power Electronic Converters (PECs) and required control algorithms provide the needed power flow versatility in the system. In the case of electrical transportation such as electric vehicles, electric vessel, electric train, etc., the power flow changes very fast depending on the operation mode of motors, generators and ESSs [2].

Hybrid ESS (HESS) provide a solution to obtain a joint enhanced performance of the global ESS with respect to the individual ESS constrained due each individual storage technology. On the other hand in applications of power system related to electric transportation (Electrical Charging Station, Vehicle to Grid (V2G), Power System Operation), the main purpose of ESS is to increase the power quality of the grid in case of line contingencies such as voltage transients, current distortions, phase unbalances, load fluctuations, islanding modes, etc [3]. Unfortunately, as mentioned previously, most current ESS ratings do not allow simultaneously a large energy capability and a fast response. This yields to the need for hybridization of at least two technologies of ESS with different characteristics, one with a high energy density and slow dynamics and other with a high power density and fast dynamics [3-8].

\section{DESIGN SPECIFICATIONS}

The system designed will be more suitable for Electric/Hybrid vessel and Electric/Hybrid train. It has the following operating conditions: Lithium Ion Battery (LIB) is selected for high power and Fast Dynamics ESS (FDESS) and Vanadium Redox Flow Battery (VRFB) is selected for high energy and Slow Dynamics ESS (SDESS). The control of VRFB is mainly to maintain the DC bus voltage constant and the control of the LIB is to provide or absorb transient power during load variations. This yields to a decrease in the power ratings of the main ESS (VRFB in this design).

The interface of both ESS is carried out by means of bidirectional boost converter as shown in Fig. 1. With this topology, the power flow of each storage device can be controlled independently thanks to the two DC/DC converters offering a high flexibility to manage the HESS [2], [9-16].

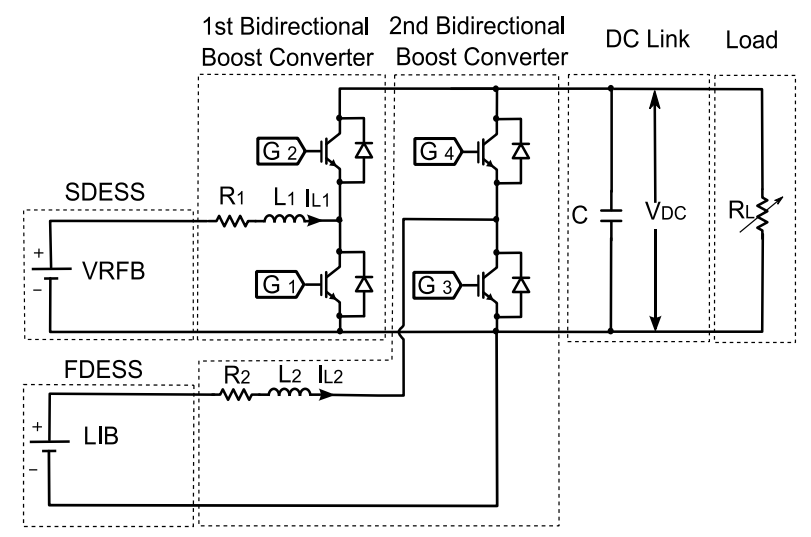

Fig. 1. The power circuit of the designed system.

\section{DESIGN METHOD}

The selection of the two batteries technologies was according to their advantages over other batteries technologies. The main advantages of VRFB are as following [4], [14-19]:

- It is an energy storage device which intended for energy rather than for power.

- Its storage efficiency is high as it can work for hours.

- It has a high scalability and is suitable for large scale storage applications because of electrolyte tanks.

- Instant recharge by electrolyte exchange. 
- $\quad$ Long life cycle up to 10000 charge/discharge cycles leads to lower through life costs.

- Low maintenance requirements because it uses pumps to circulate the electrolytes from the tanks to the cell.

Also, LIB has a lot of advantages as following [20], [21]:

- It is a power storage device compared to the VRFB.

- It has quick response than the VRFB.

- It operates through a wide range of temperatures and it has high efficiency.

- $\quad$ Easy charge controllability and low self-discharge.

- $\quad$ Suitable for short term applications.

- No pollution compared to other battery technologies.

Table 1 shows the parameters of VRFB and LIB used in the designed HESS system.

Table 1: Parameters of VRFB and LIB

\begin{tabular}{|c|c|c|c|}
\hline \multicolumn{2}{|c|}{ VRFB } & \multicolumn{2}{c|}{ LIB } \\
\hline \hline Parameters & Values & Parameters & Values \\
\hline $\mathrm{E}$ & $50 \mathrm{KWh}$ & $\mathrm{E}$ & $13.2 \mathrm{KWh}$ \\
\hline $\mathrm{V}_{\text {nominal }}$ & $25 \mathrm{KW}$ & $\mathrm{P}$ & $15 \mathrm{KW}$ \\
\hline $\mathrm{V}_{\min }$ & $1502.4 \mathrm{~V}$ & $\mathrm{~V}_{\text {nominal }}$ & $311.6 \mathrm{~V}$ \\
\hline $\mathrm{I}_{\max }$ & $166.7 \mathrm{~A}$ & $\mathrm{~V}_{\min }$ & $252 \mathrm{~V}$ \\
\hline $\begin{array}{c}\text { Operating } \\
\text { region }\end{array}$ & $20-80 \%$ & $\begin{array}{c}\text { Operating } \\
\text { region }\end{array}$ & $20-80 \%$ \\
\hline $\begin{array}{c}\text { No. of cells } \\
\text { rof }\end{array}$ & 230 & $\begin{array}{c}\text { No. of } \\
\text { batteries }\end{array}$ & 6 \\
\hline
\end{tabular}

\section{EMULATION OF THE BATTERIES}

Before Implementing the HESS with real batteries, which might be expensive, the control can be validated through the emulation of the batteries. Several options can be used to obtain the behavior of batteries.

- The first option is a real time simulation [14], however the equipment associated with this solution is very expensive.

- The second option consists on the emulation of the batteries by hardware construction by their equivalent circuit, nevertheless, if the battery parameters are changed, the hardware components should be modified as well.

- The third option is the emulation of the battery dynamics through real-time software running on a Digital Signal Processing (DSP) to get the virtual battery voltage. This last has the lowest cost and is the one analyzed in this paper.

\section{Software part}

The dynamic behavior of any battery can be modeled, among other options, by a simple circuit [1], [22], consisting of a series resistor (Rse) standing for the internal resistance of the battery, a capacitor $\left(\mathrm{C}_{\mathrm{SOC}}\right)$ representing the state of charge (SOC) and a parallel capacitor $\left(C_{D}\right)$ with a parallel resistance $\left(R_{D}\right)$ representing the dynamics of the battery as shown in Fig. 2.

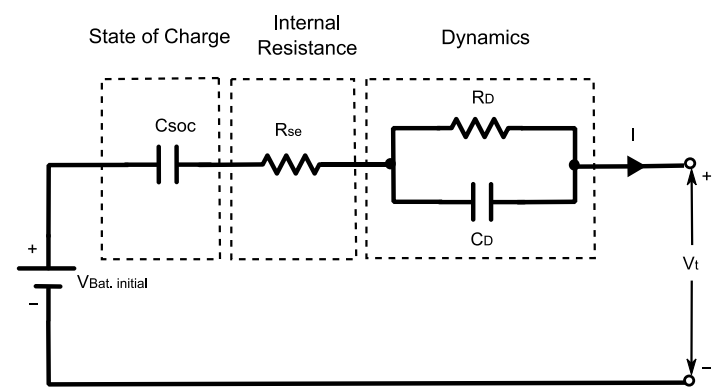

Fig. 2. Dynamic behavior equivalent circuit of any battery.

After some algebraic manipulations, the transfer function of the dynamic equivalent circuit is expressed as following:

$$
\begin{aligned}
G(s) & =\frac{V_{t}(s)-V_{\text {Bat. init. }}}{I(s)} \\
& =-\frac{R_{S} s^{2}+\left(\frac{1}{C_{S O C}}+\frac{R_{S e}}{R_{D} C_{D}}+\frac{1}{C_{D}}\right) s+\frac{1}{R_{D} C_{D} C_{S O C}}}{s^{2}+\frac{1}{R_{D} C_{D}} s}
\end{aligned}
$$

where:

- $\mathrm{V}_{\mathrm{t}}(\mathrm{s})$ : is the terminal voltage of the equivalent circuit,

- $\mathrm{I}(\mathrm{s}) \quad$ : is the current flowing in the equivalent circuit,

- $\mathrm{V}_{\text {Bat. init }}$ : is the initial battery voltage,

- $\mathrm{s} \quad$ : is the Laplace transform.

The current is considered positive flowing out of the battery (Discharging mode), thus a negative sign appears in (1). The virtual voltage of the battery is calculated in (2) from the transfer function. Also, the initial conditions of the battery voltage are included in the virtual voltage. Equation (2) is implemented in the DSP to get the virtual battery voltage which presents the same dynamics as the real battery voltage. The parameters of the dynamic equivalents circuit of both batteries are shown in table 2 .

$$
\begin{aligned}
V_{\text {Bat. virtual }}(s) & =V_{t}(s) \\
& =V_{\text {Bat. init. }}+I(s) * G(s)
\end{aligned}
$$

Table 2: Parameters of the dynamic equivalent circuits of VRFB and LIB

\begin{tabular}{|c|c|c|c|}
\hline \multicolumn{2}{|c|}{ VRFB } & \multicolumn{2}{c|}{ LIB } \\
\hline \hline Parameters & Values & Parameters & Values \\
\hline C $_{\text {SOC }}$ & 7594.9 Farads & C $_{\text {soC }}$ & 0.0127 Farads \\
\hline $\mathrm{R}_{\mathrm{se}}$ & 0.06826 Ohms & $\mathrm{R}_{\mathrm{se}}$ & 0.0628 Ohms \\
\hline $\mathrm{C}_{\mathrm{D}}$ & 0.025 Farads & $\mathrm{C}_{\mathrm{D}}$ & 0.0127 Farads \\
\hline $\mathrm{R}_{\mathrm{D}}$ & 0.0996 Ohms & $\mathrm{R}_{\mathrm{D}}$ & 0.1181 Ohms \\
\hline
\end{tabular}

\section{Hardware part}

To obtain the initial battery voltage in (2), a three phase uncontrolled rectifier as in Fig. 3. Capacitors are intended to decrease the ripples and smoothing the DC voltage. A charging resistance is used to initially charge the capacitor smoothly and then the bypass switch is closed. A blocking diode is used to prevent power return back to the three phase uncontrolled rectifier. A burning resistance is used to discharge the capacitor and in case of the power flowing from the DC bus through the bidirectional boost converter to the three phase rectifier, the burning resistance will 
dissipate the power flowing back like in case of regenerative applicants. For this system, the two circuits of the FDESS and SDESS are similar, but with different initial voltage values.

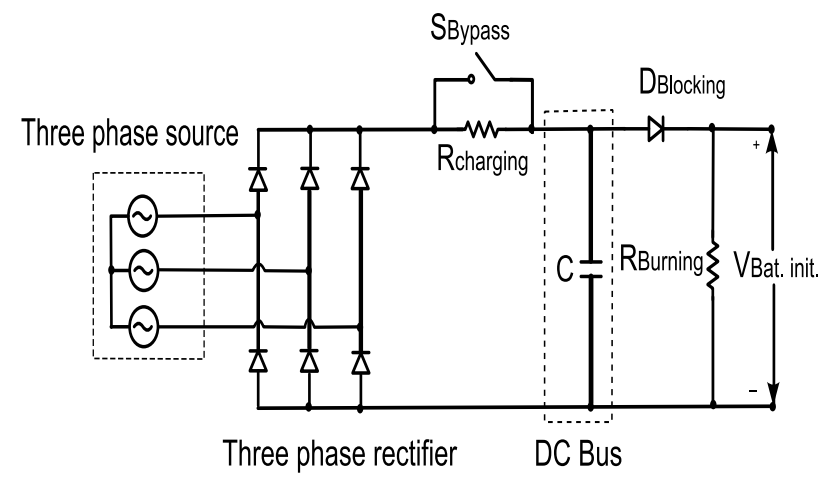

Fig. 3. Emulation of the battery to obtain the initial voltage of the battery and behaves as a battery.

\section{CONTROL SCHEME OF THE CONVERTERS}

As mentioned, the system consists of two bidirectional DC-DC boost converters. Each converter is connected to one battery and has its own control. One converter controls the DC link voltage to avoid stability problems, while the other converter delivers the peak transient power during load variations.

As discussed in the previous section, the virtual voltage of each battery will be calculated from (2) as in Fig. 4, however, each equivalent circuit has its own parameters. As the control of SDESS bidirectional boost converter is to maintain the DC link voltage constant. A typical cascaded control scheme is used, being the outer loop the DC link voltage control and the inner loop the inductor current control [6], [23]-[27] as shown in Fig. 5.

The control aim of the FDESS bidirectional boost converter is to provide the peak transient power when the load varies. This control will accelerate the recovery of the DC link voltage variations. Also cascaded control scheme is proposed, being the outer loop the power control and the inner loop the inductor current control as shown in Fig. 6.

The power reference is calculated by subtracting to the SDESS measured power its low frequency component by using a Low Pass Filter (LPF) to get the high frequency component.

To assure that the power of LIB is providing transient power during load variations, a PI controller is implemented. To increase the amount of power provided by the LIB, a gain $\mathrm{K}$ is multiplied by the power measured of the LIB. This means that more power will be released under sudden load variations, as the power error tends to increase the FDESS current reference. This will be helpful for the fast recovering of the DC link voltage. The value of the gain $\mathrm{K}$ goes from 0.1 to 1.0 and it depends on the maximum power of FDESS and the load variations. Table 3 shows the parameters of the control scheme of both converters.
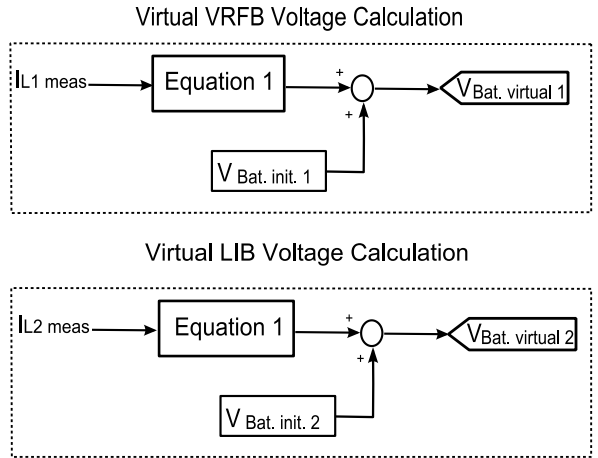

Fig. 4. Virtual voltage calculation for VRFB and LIB to get the battery dynamics.

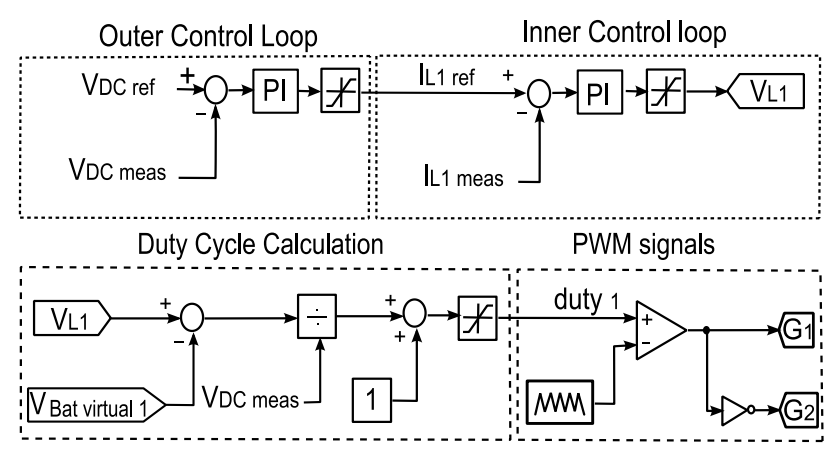

Fig. 5. SDESS converter control scheme to maintain the DC link voltage constant.

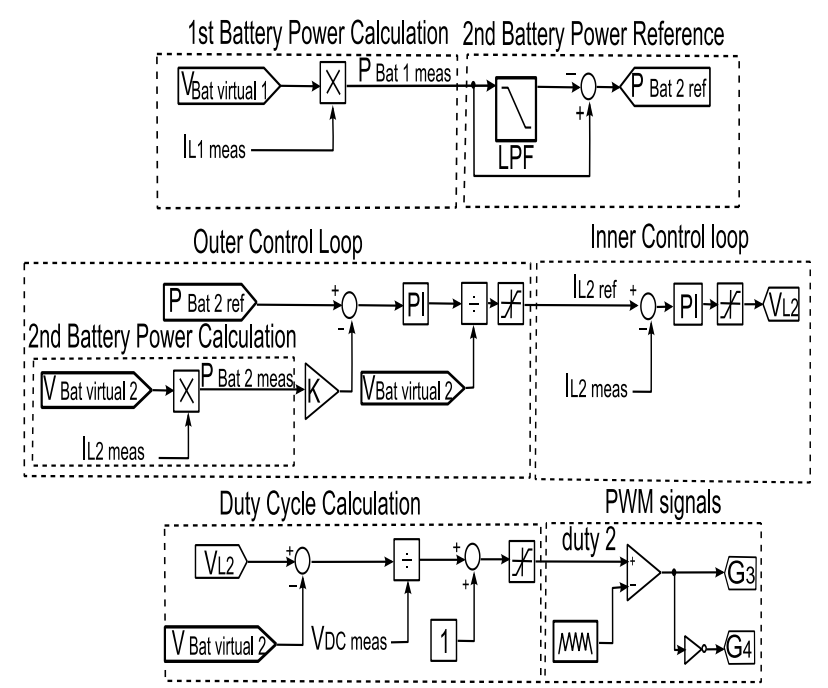

Fig. 6. FDESS converter control scheme to provide transient power during load variations.

Table 3: Parameters of the control scheme

\begin{tabular}{|c|c|c|c|}
\hline \hline Parameters & Values & Parameters & Values \\
\hline \hline$V_{\text {VRFB init. }}$ & $302.4 \mathrm{~V}$ & V $_{\text {LIB init }}$ & $311.6 \mathrm{~V}$ \\
\hline \multicolumn{4}{|c|}{ SDESS converter control parameters } \\
\hline V $_{\text {DC ref }}$ & $600 \mathrm{~V}$ & $\mathrm{~F}_{\mathrm{s}}$ & $10 \mathrm{KHz}$ \\
\hline $\mathrm{K}_{\mathrm{pv}}$ & 0.19 & $\mathrm{~K}_{\mathrm{pi}}$ & 79.16 \\
\hline $\mathrm{T}_{\mathrm{iv}}$ & 0.3 & $\mathrm{~T}_{\mathrm{ii}}$ & 0.042 \\
\hline \multicolumn{4}{|c|}{ SDESS converter control parameters } \\
\hline $\mathrm{F}_{\text {LPF }}$ & $10 \mathrm{~Hz}$ & $\mathrm{~F}_{\mathrm{S}}$ & $10 \mathrm{KHz}$ \\
\hline $\mathrm{K}_{\mathrm{pp}}$ & 1.56 & $\mathrm{~K}_{\mathrm{pi}}$ & 79.16 \\
\hline $\mathrm{T}_{\mathrm{ip}}$ & 1 & $\mathrm{~T}_{\mathrm{ii}}$ & 0.042 \\
\hline
\end{tabular}




\section{VERIFICATION OF THE DESIGNED SYSTEM WITH SIMULATIONS}

The simulations will consist on applying load variations upon the system once the demanded power has reached the steady state, with different values of gain $\mathrm{K}$, using as a metric the DC link voltage variations.

A voltage reference of $600 \mathrm{~V}$ is used to validate the proposed control scheme for the designed HESS. The load is varied from $1.2 \mathrm{KW}$ to $2.4 \mathrm{KW}$ and again to $1.2 \mathrm{KW}$. The system is tested for two cases to check the effect of connecting LI-IB to VRFB.

- Case 1. Only VRFB is used, being connected to the DC link through the bidirectional boost converter.

- Case 2. Both VRFB and LI-IB are connected to the DC link by means of two bidirectional boost converters.

In Case 1, as shown in Fig. 7 that the DC link voltage drops $18 \mathrm{~V}$ when load varies from $1.2 \mathrm{KW}$ to $2.4 \mathrm{KW}$ and increases $19 \mathrm{~V}$ when load varies from $2.4 \mathrm{KW}$ to $1.2 \mathrm{KW}$. These changes in the DC link voltage will increase if the load power is increased as the system designed for $25 \mathrm{KW}$.
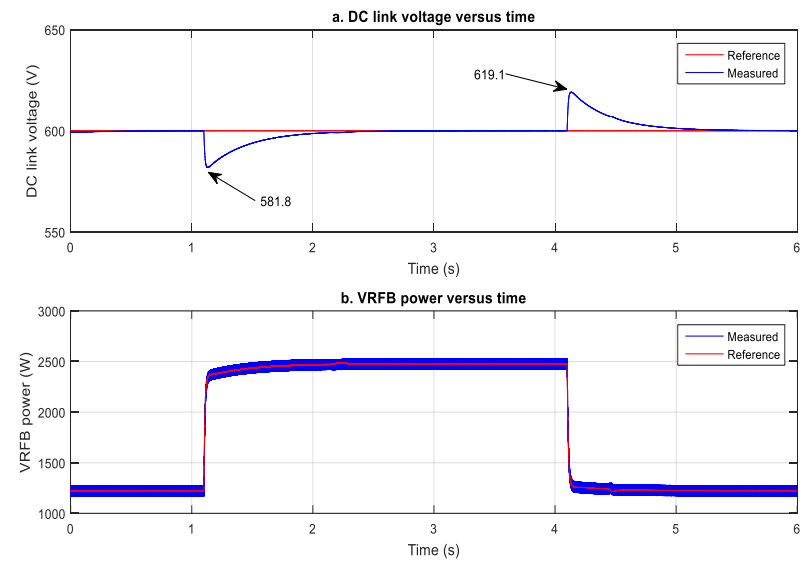

Fig. 7. Simulation Results at VRFB only: a) DC link voltage versus time b) VRFB power versus time.

In case 2, the gain $\mathrm{K}$ in Fig. 6 is changed to check the effect on the DC link voltage and the LI-IB current. As starting value, $\mathrm{K}=1.0$ is selected, the DC link voltage variations already exhibit a decrease, this is due to the power delivered by the LI-IB when load varied. By further decreasing $\mathrm{K}$, the maximum voltage variations also improves, as it is shown in table 4, thus minimizing the effect of the load variations in the DC link voltage. The selected optimal value for $\mathrm{K}$ is 0.3 and the results are shown in Fig. 8.

Table 4: Simulation Results

\begin{tabular}{|c|c|c|c|c|c||}
\hline \hline & K & $\begin{array}{c}\text { V } \\
\text { DC_min } \\
(\mathrm{V})\end{array}$ & $\begin{array}{c}\text { V }_{\text {DC_max }} \\
(\mathrm{V})\end{array}$ & $\begin{array}{c}\text { PLIB max } \\
(\mathrm{W})\end{array}$ & $\begin{array}{c}\text { PLIB min } \\
(\mathrm{W})\end{array}$ \\
\hline \hline Case 1 & & 581.9 & 619.1 & & \\
\hline Case 2 & 1.0 & 587.9 & 612.7 & 465.8 & -463.1 \\
\cline { 2 - 6 } & 0.7 & 588.5 & 612.2 & 531.3 & -529.1 \\
\cline { 2 - 6 } & 0.5 & 588.8 & 611.2 & 581.8 & -552.3 \\
\cline { 2 - 6 } & 0.3 & 589.9 & 610.4 & 655.7 & -580.7 \\
\hline
\end{tabular}
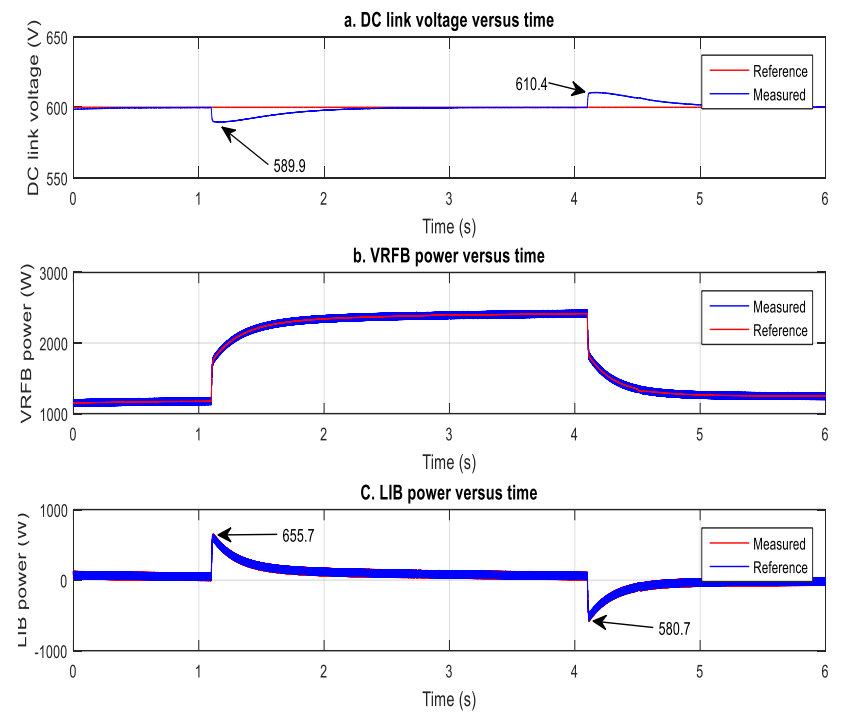

Fig. 8. Simulation Results when VRFB and LIB are connected at $\mathrm{K}=0.3$ : a) DC link voltage versus time. $\mathrm{b}$ ) VRFB power versus time. c) LIB power versus time.

\section{VERIFICATION OF THE DESIGNED SYSTEM WITH EXPERIMENTAL SETUP}

As it has been mentioned, the dynamic behavior of both the LDESS and FDESS will be implemented in real time software with parameters in Table 2, and the power will be absorbed or delivered to a dedicated DC bus. This scheme can be replicated for any ESS technology, provided that the dynamic behavior is known or can be calculated.

The experimental results in Fig. 9 and table 5 are to validate the emulation of the batteries and the proposed control scheme.
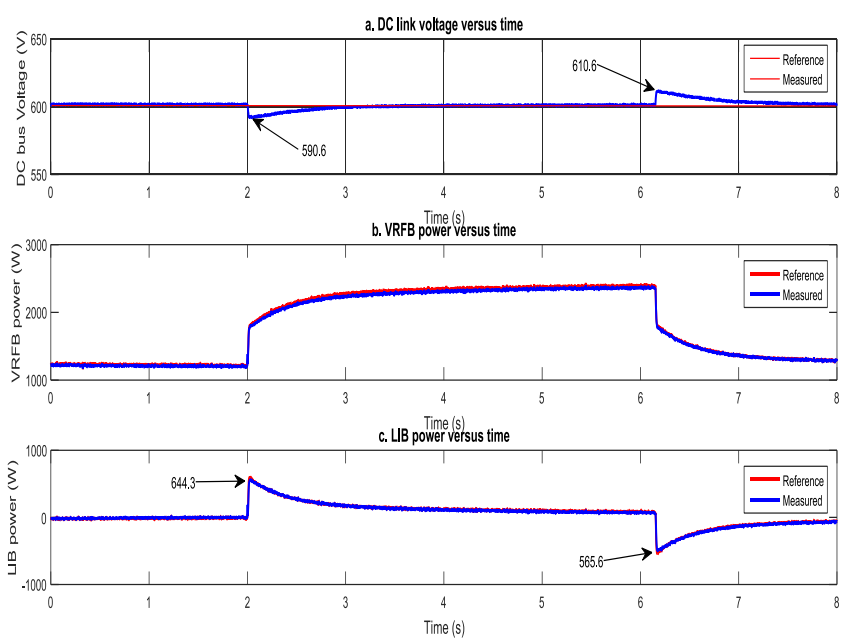

Fig. 9. Experimental Results when VRFB and LIB are connected at $\mathrm{K}=0.3$ : a) DC link voltage versus time $\mathrm{b}$. VRFB power versus time. c) LIB power versus time.

Table 5: Experimental Results

\begin{tabular}{||c|c|c|c|c|c||}
\hline \hline & $\mathrm{K}$ & $\begin{array}{c}\mathrm{V}_{\text {DC_min }} \\
(\mathrm{V})\end{array}$ & $\begin{array}{c}\mathrm{V}_{\text {DC_max }} \\
(\mathrm{V})\end{array}$ & $\begin{array}{c}\text { PLIB max }_{\text {max }} \\
(\mathrm{W})\end{array}$ & $\begin{array}{c}\text { P LIB min } \\
(\mathrm{W})\end{array}$ \\
\hline \hline Case 1 & & 583 & 619 & & \\
\hline Case 2 & 1.0 & 587.7 & 612.7 & 454.9 & -442.5 \\
\cline { 2 - 6 } & 0.7 & 588.3 & 611.6 & 502 & -503.2 \\
\cline { 2 - 6 } & 0.5 & 589.1 & 611.1 & 567.7 & -523.8 \\
\cline { 2 - 6 } & 0.3 & 590.6 & 610.6 & 644.3 & -565.6 \\
\hline
\end{tabular}




\section{CONCLUSION AND FUTURE WORK}

The designed HESS system for electric transportation decreases the total cost as there is no need to have a main ESS with a high energy density and a high power density simultaneously. Also it increases the life span of the main ESS.

The designed system with the proposed control scheme is validated by simulation and experiments. The simulation results are validated with the experimental results from emulation of the batteries. This emulation of batteries provide a low cost solution to test any technology of batteries and can validate any new control scheme before implementing HESS.

The technique used for emulation can be extended to different battery technologies, only requiring software changes. Further, the proposed control scheme can be used for any ESS technology such as supercapacitors, regular capacitors, etc.

Moreover, future developments of this work would include: increasing the number of ESS in the hybrid system and explore the applicability to other PEC topologies, such as isolated, multilevel, etc.

\section{ACKNOWLEDGMENT}

I would like to thank Prof. Pablo Garcia for his guidance and supporting. This work has been partially supported by the Spanish Government, Innovation Development and Research Office (MEC), under research grant ENE201344245-R, Project "Microholo", and by the European Union through ERFD Structural Funds (FEDER). Also, this work has been partially supported by the government of Principality of Asturias, Foundation for the Promotion in Asturias of Applied Scientific Research and Technology (FICYT), under Severo Ochoa research grant, PA-13-PFBP13138.

\section{REFERENCES}

[1] A.R. Sparacino, G.F. Reed, R.J. Kerestes, B.M. Grainger, Z.T. Smith, "Survey of battery energy storage systems and modeling techniques," 2012 IEEE in Power and Energy Society General Meeting, 22-26 July 2012, pp.1-8.

[2] Yoo, H., Seung-Ki Sul, Yongho Park, Jongchan Jeong, "System Integration and Power-Flow Management for a Series Hybrid Electric Vehicle Using Supercapacitors and Batteries," IEEE Transactions on Industry Applications, vol.44, no.1, pp.108,114, Jan.-feb. 2008.

[3] J. Cobben, W. Kling, and J. Myrzik, "Power quality aspects of a future micro grid," in International Conference on Future Power Systems. IEEE, Nov. 2005, pp. $1-5$.

[4] Vechiu, A. Etxeberria, H. Camblong, and J. M. Vinassa, "Three-level neutral point clamped inverter interface for flow battery/supercapacitor energy storage system used for microgrids," in PES International Conference and Exhibition on Innovative Smart Grid Technologies (ISGT Europe), no. 2. IEEE, Dec. 2011 , pp. $1-6$.

[5] B. Wang, B. Zhang, and Z. Hao, "Control of composite energy storage system in wind and pv hybrid microgrid," in International Conference of IEEE Region 10 (TENCON). IEEE, Oct. 2013, pp. 1 - 5 .
[6] D. Tran, H. Zhou, and A. M. Khambadkone, "Energy management and dynamic control in composite energy storage system for micro-grid applications," in Annual Conference of IEEE Industrial Electronics Society (IECON), no. 36. IEEE, Nov. 2010, pp. 1818 - 1824.

[7] Etxeberria, I. Vechiu, H. Camblong, A. Etxeberria, J. Vinassa, and H. Camblong, "Hybrid energy storage systems for renewable energy sources integration in microgrids: A review," in IPEC. IEEE, Oct. 2010, pp. 532 - 537.

[8] S. priya.S and Rajakumar.S, "An energy storage system for wind turbine generators- battery and supercapacitor," International Journal of Engineering Research and Applications (IJERA), vol. 3, pp. 1219 - 1223, March - April 2013.

[9] Tummuru, N.R., Mishra, M.K., Srinivas, S., "Dynamic Energy Management of Hybrid Energy Storage System With High-Gain PV Converter," IEEE Transactions on Energy Conversion, vol.30, no.1, pp.150,160, March 2015.

[10] Kollimalla, S.K., Mishra, M.K., Narasamma, N.L., "Design and Analysis of Novel Control Strategy for Battery and Supercapacitor Storage System," IEEE Transactions on Sustainable Energy, vol.5, no.4, pp.1137, 1144, Oct. 2014.

[11] Kollimalla, S.K., Mishra, M.K., Lakshmi Narasamma, N., "Coordinated control and energy management of hybrid energy storage system in PV system," 2014 International Conference on Computation of Power, Energy, Information and Communication (ICCPEIC), pp.363,368, 16-17 April 2014.

[12] Sathishkumar, R., Kollimalla, S.K., Mishra, M.K., "Dynamic energy management of micro grids using battery super capacitor combined storage," 2012 Annual IEEE India Conference (INDICON), pp.1078, 1083, 7-9 Dec. 2012.

[13] Jayasinghe, S.D.G., Vilathgamuwa, D.M., Madawala, U.K., "A direct integration scheme for battery-supercapacitor hybrid energy storage systems with the use of grid side inverter," 2011 Twenty-Sixth Annual IEEE Applied Power Electronics Conference and Exposition (APEC), pp.1388, 1393, 6-11 March 2011.

[14] Wei Li; Joos, G., Belanger, J., "Real-Time Simulation of a Wind Turbine Generator Coupled with a Battery Supercapacitor Energy Storage System," IEEE Transactions on Industrial Electronics, vol.57, no.4, pp.1137, 1145, April 2010.

[15] Wei Li; Joos, G., "A power electronic interface for a battery supercapacitor hybrid energy storage system for wind applications," IEEE Power Electronics Specialists Conference, 2008. PESC 2008, pp.1762, 1768, 15-19 June 2008.

[16] C. A. Smith D. D. Banham-Hall, G. A. Taylor and M. R. Irving, "Frequency control using vanadium redox Flow batteries on wind farms", In IEEE, 2011.

[17] C. Abbey J. Chahwan and G. Joos, "VRB modelling for the study of output terminal voltages, internal losses and performance", In IEEE Canada Electrical Power Conference, 2007.

[18] Wu Bingyin Mao Biao, Zhang Buhan and Xie Guanglong, "Studies on security capacity of wind farms containing vrb energy storage system", In Mao Biao, pages 1704 - 1708.

[19] Daqiang Bi Wenliang Wang, Baoming Ge and Dongsen Sun, "Grid-connected wind farm power control using VRB-based energy storage system", In IEEE, pages 3772 - 3777, 2010.

[20] John A. Chahwan, "Vanadium-Redox Flow and lithium-ion battery modelling and performance in wind energy applications", Master's thesis, McGill University, Montreal, Quebec, May 2007.

[21] Ye Zhang Li Guo and Cheng Shan Wang, "A new battery energy storage system control method based on SOC and variable filter time constant", In IEEE, 2011.

[22] M. Gonzaleza V.M. Garciab C. Blancoa D. Anseana, J.C. Vieraa and J.L. Antunaa, "Meaurement and study of $\mathrm{dc}$ internal resistance in lifepo4 batteries", In EEVC European 
Electric Vehicle Congress, Brussels, Belgium, November 2012.

[23] L. Baoquan, Z. Fang, and B. Xianwen, "Control method of the transient compensation process of a hybrid energy storage system based on battery and ultra-capacitor in micro-grid," in International Symposium on Industrial Electronics (ISIE). IEEE, May 2012, pp. 1325 - 1329.

[24] D. D. Banham-Hall, G. A. Taylor, C. A. Smith, and M. R. Irving, "Flow batteries for enhancing wind power integration," IEEE Transactions on Power Systems, vol. 27, no. 3, pp. 1690 - 1697, Aug. 2012.

[25] H. Kakigano, Y. Miura, T. Ise, and R. Uchida, "Dc microgrid for super high quality distribution - system configuration and control of distributed generations and energy storage devices -," in Power Electronics Specialists Conference. IEEE, June 2006, pp. $1-7$.

[26] J. Liang and C. Feng, "Stability improvement of micro-grids with coordinate control of fuel cell and ultracapacitor," in Power Electronics Specialists Conference (PESC). IEEE, June 2007, pp. $2472-2477$.

[27] L. Barote, C. M. Weissbach, R. Teodorescu, C. Marinescu, and M. Cirstea, "Stand-alone wind system with vanadium redox battery energy storage," in International Conference on Optimization of Electrical and Electronic Equipment (OPTIM), no. 11. IEEE, May 2008, pp. $407-412$. 